circulation, or which produce a specific corroborant $\mid$ our minds with reference to surgical procedures. influence upon the heart center, reduce temperature, Therre was a time-and it is not so far in the past thereby diminishing heat production, while those that we can not witness living examples of the factwhich dilate the vascular (cutaneous) system cause when cases of hip-joint disease went unrecognized. the thermal loss. Antipyrin, phenacetin, lactophenin, I do not say they do not go without recognition and their congeners do certainly increase radiation by today - I wish I could. But, with the advent of new circumscribing the tissue metamorphoses. As high ideas, new methods have taught us more of the suban authority as Shoemaker - and in my opinion there ject, and now fewer cases are overlooked than at any is none bigher-states that phenacetin is not toxic in time in the history of surgery.

ordinary doses, but I have had some cases to whom I Much valuable time is lost in many cases by the administered it which caused me great anxiety. One, diagnosis of rheumatism or "growing pains," and I am in particular, a woman suffering from dysmenorrhea compelled to admit, in deference to those who treat (congested form), to whom I gave four 10-grain doses, the condition in its early manifestations from that four hours apart, had alarming prostration, uncon- standpoint, that their error seems excusable, for there trollable emesis, vertigo, profuse perspiration, with is quite a similarity, in a general way, in the very urticarial rash and deep cyanosis. Possibly, how- early stages of the seizure. But when such a diagever, I may have used an impure product, made by imperfect conversion of paraphenacetidin into phenacetin. Lately, I have tried lactophenin, a closelyallied product to phenacetin - with better results. Still, I was not entirely pleased with it, as it acted on the beart too strongly. The best one of the lot, which has given me entire satisfaction in dysmenorrhea and typhoid fever, is ammonol. It reduces the temperature without exerting any depressant cardiac action; on account, I suppose, of ammonia, with which it is combined. Dr. Francis E. Stewart, chairman of the National Legislation of the American Pharmaceutical Association says that practically all synthetic compounds are foreign made, and their manufacturers or agents have secured letters patent for the processes of making, or copyright protection of their names. In nearly all cases, not an ounce is made in this country; no native industry is protected, but a foreign made product is imported through an agent to whom the sick of the country are made to pay tribute. Were these agents content to accept reasonable profits there would be less ground for complaint, but when phenacetin sells in Great Britain for $\$ 1.25$ a pound, and in the United States for $\$ 1.00$ an ounce, the tax on the public becomes burdensome, and the ruling of the patent office, which makes such a condition of affairs possible, demands protest.

If I have succeeded in impressing one member of my beloved profession with the necessity of using circumspection in exhibiting these coal-tar products indiscriminately, then I am content, and I feel assured that then the afflicted may exclaim, "AEgroto dum anima est, spes est," for then, indeed, "to the sick while there is life there is hope."

\title{
THE RADICAL TREATMENT OF DISEASE OF THE HIP-JOINT.
}

Presented to the Wyoming State Medical Society, Nov. 1. 1898. BY CHARLES G. PLUMMER, B.S., M.D. SALT LAKE CITY, UTAH.

During the past two or three decades we have te learned much in the treatment of disease of the hipjoint. Some of our knowledge is the direct result of years of research, yet more has the freshness and nearness of the teachings of men of our own age. The equipment of recent graduates in the theoretic treatment of this class of ailments is immense, but what they lack is the illustrated application. This we call experience. It is that something which we do not attain didactically - it only comes by personal contact. This fact holds equally good with almost any subject we might mention, but it is especially impressed upon nosis is made and treatment instituted and maintained, where the cardinal points which go to make up the diagnosis of hip-joint disease are in evidence, the mistake is culpable. To be sure, neurotic reflexes with symptoms referable to the region of the hip and knee, such as preputial adhesions, anal fissures, or rectal ulcerations, have misled many most excellent men. I believe it is the search for some of these little things wherein lie our most pronounced successes. With their removal, or the elimination of their possible existence, our diagnosis is so much easier. Still, when we take into consideration the fact that the great majority of these cases occur in childhood or early youth, we may be pardoned when we say we sometimes meet cases wherein a diagnosis is not easy.

Children are so apt to magnify their ailments, they are often so unmanageable and reticent that our diagnosis is almost wholly subjective. It is sometimes impossible to conclude positively that we have morbus coxarius, from a single inspection and examination. It will pay us to keep the suspected case under close observation, seeing it perhaps every few days, with instructions to the family to look for certain prominent symptoms, upon which we are to base our conclusions. We may not observe in any one case all the pathognomonic signs of the disease, still when we see the marked flexion and abduction of the limb, either in the prone or upright position, the limited motion, the apparent ankylosis at the hip, night pains and pains referred to the knee, we can not miss it much by pronouncing it coxitis. Perhaps the subject has suffered some traumatism, perhaps not-it does not matter, for whatever the cause, the treatment is identic.

In coming to the question of treatment, I wish to state that I believe all the successful methods of treating hip-joint disease today may be termed radical. That there are degrees of radicalism we can not deny. Looking upon the results of treatment of these cases in the hands of some whom we might term antiradicals, or extremists in conservatism, I am not much impressed with the wisdom of their medico-supportive and expectant methods. The physician who allows a case to progress so far as to permit of the formation of abscess in or about the region of the hip-joint makes a grave error. And one who has not seen cases of advanced disease of the joint will find that he is totally unable to appreciate the terrific ravages such abscesses will commit. Extensive suppurative sinuses will penetrate the deeper structures of the hip and thigh, extending in some cases down the leg to the knee, forming large 
bulging pockets of pus in the popliteal space, or above the patella; or they will burrow beneath the gluteal muscles across to the other side, or come out under Poupart's ligament, or through the ischiorectal region. And just as sure as hip-joint abscess develops, deformity in some degree may be expected.

My experience has taught me that every deformity - by which I mean modified or absolute ankylosis with shortening resulting - is due either to abscess, or neglect and deferred treatment. Why is such deformity in evidence? Often because of the expectant and medicinal treatment of misguided conservatism. Do not misunderstand me, please, for I believe in every endeavor to prove the value of conservative measures; but there comes a time when conservatism is not a synonym for good sense, when delay is dangerous, when hesitancy loses the day. For just such cases as these radical surgical procedure is necessitated. Radical treatment means the institution of active surgical measures, as opposed to the delay, linger-and-wait methods of the ultraconservative. My interpretation of radical advances begins with the use of injections of emulsions of iodoform, iodin, or any other drug into or about the joint cavity; or with extension alone; or with extension combined with hypodermatic injections at the site of the disease, of Vaughan's nuclein solution; or with resection of the head of the femur and thorough removal of all evidences of the disease.

I have purposely refrained from saying anything about the etiology of hip-joint disease, for I am certain we are a unit on that subject, if not entirely so on that of treatment. My reading and my own experience convince me that morbus coxarius has its ori. gin in the tubercle bacilli; hence it is merely a circumscribed tuberculosis. It does not matter whether there be a cachexia or not, or whether it result from a traumatism, I believe the cause always the same. One may not always be able to demonstrate the tubercle bacillus, he can not find it every time he examines the sputum of a tuberculous subject; nevertheless, the existence of foci of disease absolutely characteristic in every particular proves the origin to be one and the same.

While the name "hip-joint disease" is used to designate a tubercular inflammation of the hip-joint, it may have its origin in any one of three places: first, on the femur, called epiphyseal; second, acetabular; and third, arthritic, or synovial. The place of its origin has something to do with its treatment later. If it begins, as is usual in the majority of cases, among children especially, in the epiphysis, the treatment must be more rapidly enforced, and of a much greater degree of severity. For my own convenience, I have divided radical measures into three classes: 1 , injections of drugs into or about the joint cavity; 2 , the employment of extension; 3 , resection of the head of the femur.

In the first and second classes, as I have already in. dicated, we may use a combination of methods to suit the exigencies of the case, and to promote the best results. For instance, one would not give intra-articular injections of iodoform emulsion and allow the patient to perform his ordinary duties, because rest is one of the first considerations. So with a judicions use of the very best means combined, it becomes our function to save the vast majority of cases from the dreaded fate of the last degree of radical surgical procedure, viz., resection of the hip-joint.
Upon the recognition of a case of hip disease, no matter what the age of the patient, the tripod of success is: 1 , perfect immobilization with the Thomas splint; 2 , the prone position; 3 , extension. Without any other means whatever, I feel confident, in at least 90 per cent. of all cases, of securing the best results, when the above rules are strictly adhered to, and intelligently carried out. With the intra-articular and parenchymatous injection of a 10 per cent. emulsion of iodoform in glycerin, properly sterilized, we get better results than with a similar use of any other of the numerous solutions that have come before the profession. This treatment has been followed some years, but is, properly speaking, one of the weapons of moddern surgery. Since the discovery that the tubercle bacilli existed in the so-called cold abscesses and joint affections, its employment has been more a matter of scientific application, with results directly proportionate to the thoroughness with which it is carried out.

Sometimes iodoform intoxication occurs among those who are particularly susceptible, but it is infrequent and rarely of much violence. Nevertheless, in its administration one should give but from twenty to thirty grains, according to the age of the patient, at the first treatment, and watch the effect. If the patient bears it well, it may be increased to a much larger dosage. After we are satisfied of the existence of disintegrating material, boldly plunge a small, perfectly sterilized canula into the capsule, or the body of the abscess, and draw off all the contents. Leave the canula in position, and with an aseptic rubber tube attached to it, thoroughly irrigate the interior with a warm Thiersch solution, or a 2 to 4 per cent. solution of boric acid. Continue irrigating until the returning solution is perfectly clear, then fill the cavity moderately full of the iodoform emulsion, remove the canula, and place over the opening a close aseptic dressing. The parenchymatous injection is about as effective as the intra-articular, and the same technic is employed.

In the hands of many surgeons, balsam Peru, corrosive sublimate, iodin, carbolic acid, and arsenious acid have proved of more or less value in their antibacterial action. The violent inflammation set up by the most of these agents is a hindrance to their more general adoption, so that iodoform in glycerin is much more popular. Different operators publish a variety of statistics on the employment of iodoform in this manner, some going so far as to absolutely deny any antibacterial action whatever, while others consider it the best and most curative agent in our hands. As far as I am able to judge of its value in the few cases in which I have used it, I believe it has a definite, germicidal power, depending largely, as a cure, on the stage of the diseased process wherein it is used. True, I have not always found the tubercle bacillus in the gross discharges from such a condition-it is sometimes quite difficult - neither can we always attest the infallibility of the Widal test in typhoid fever; yet, to him who has come in contact with very many representatives of these diseases, the phases are so pertinent, that a mistake in diagnosis is improbable. And we are certain, absolutely so, in spite of all the tests, that the above diseases exist, even when their bacilli can not be demonstrated. So much for the first method of treatment alone, which may be combined with the second, that of extension, and often to great advantage.

As I have previously declared, the success of treat- 
ment by extension depends on perfect immobilization of the affected part, and rest in the prone position, during the acute stages at least. I am unwilling to admit that a patient can do as well with the joint immobil. ized and be allowed to go on crutches. The great requisite is rest for the joint and also for the tissues enveloping it. No one can be sure of the entire abcence of muscular, and even of joint motion, when a patient is in the upright position. And it is this perfect rest, with separation of the diseased synovial membranes, upon which we base our assumptions for relief and cure. We know full well how little motion or disturbance can be borne by the sufferer, when we attempt to make an examination of the hip-joint without anesthesia. It does not appear that age wakes much difference; from extreme childhood to old age the excruciating agony they endure upon the slightest motion goes to show why perfect rest is best.

One of the best means for securing immobility is the Thomas splint, perfectly fitted, applied and maintained. I do not deem it always requisite to use this splint. In adult cases it is not needed as much as among children. Where immobilization can not be secured by ordinary bandaging for extension, then the Thomas splint is the best appliance known. Its use should be maintained after the acute stage has passed, and the patient is allowed to go about on crutches, with a patten under the foot of the well leg.

Another most beneficial agent incorporated in the armamentarium of the surgeon for the treatment of this condition, is Vaughn's nuclein solution as produced by Parke, Davis \& Co. I have used it in conjunction with extension in a number of cases. In one case, that of a man aged 44 years, it was not administered hypodermatically. I gave him the 5 per cent. solution by the mouth in rapidly increasing doses, until he was taking 60 minins four times daily. From the very beginning an attempt was made to thoroughly saturate him with the nuclein, and the happy results more than repaid us. A rapid decrease in the swelling about the hip-joint took place, the tenderness wholly disappeared, his appetite improved, and there was a complete subsidence of the usual train of annoying symptoms, that rarely, in previous cases, had been accomplished by extension alone. During the incarceration of this patient's hip-joint, he gained over twenty pounds in weight. He had previously undergone amputation of the foot, on the same leg that now suffered from hip disease, for tuberculosis of the ankle. At the time the extension apparatus was adjusted there were several small tubercular ulcers on the tibia above the stump; hence it was not without misgivings that radical treatment was instituted. And I feel compelled to admit that without such a powerful agent as Vaughn's nuclein solution, producing a vigorous leucocytosis, the result in this case could not have been good. The great increase in the diseaseresisting power afforded the human body by such an element, its germicidal influence and antiseptic properties, recommend it very strongly to our consideration in these cases. Experimenters speak of it very highly also, in cases of mixed infection. Its use, either by the mouth or hypodermatically, is attended by no evil results. I presume I have given nearly 1000 injections of it, and have had as yet no needle abscess--something one can not say of all the various antitoxins we use nowadays.

The third and most extreme measure adopted for the treatment of this disease, resection of the hip-land details pursued, but it is not pertinent at this joint, I have found it necessary to employ three times. It is so radical, and the deformity is so marked, that one hesitates to resort to it, often putting off the evil day until he feels he is not doing the patient or him. self justice. Some writers may deem it the only treatment employed that might be termed radical. To be sure, it is the extreme of radicalism, but is demanded in a certain class of cases. There are degrees of severity of the invasion of the hip-joint by the tubercle bacillus, just as there are of any other disease with which we come in contact. One type we can treat by a measure as rudical as any other, because it singles out the cause and eradicates it; another by means just as effective and as far-reaching, but perhaps not so brilliant; and a third by the lastresort method, the sacrifice of more or less tissues, but the permanent removal of all growth interfering with local and general recovery.

Surgical good sense, for which conservatism is so often and improperly used as a synonym, should be the bulwark of every well and properly-equipped operator. With a case in hand, one can not go over the ground and make an operation of selection, for you have something to do other than a mere removal of the head of the femur. The anatomic relations are so changed that one would scarcely recognize the vicinity, and the attack on the great bulging, sloughing mass can not be made upon any hard and fast lines. The idea is to get to the seat of the trouble as rapidly as possible, and with the loss of as little tissue as is practicable, and at the same time be thor. ough. The simple resection of a practically normal case is nothing compared with what confronts one in a last stage case. The amount of pus that can burrow around the hip and pelvis, and the amount of disintegrated tissue that comes away through a free incision is astonishing. The removal of all adjacent diseased tissue and the scraping of the foci are secondary to the rapid and careful resection of the head of the bone. Remove all signs of disease, but leave all the bone that it is possible to leave. In doing the section, leave the great trochanter, if possible; if it must be sacrificed, saw through it just above the lesser trochanter at an angle, thus maintaining the integrity of the muscular attachment for the great muscles of the thigh.

Notwithstanding the deformity which must result from the removal of such an important factor, it is neither as great nor as maiming as that which follows the usual suppurative processes involving the hipjoint, when allowed to heal by natural resolution. Resection presents the horrors of an operation to patient and relatives. It also guarantees speedy and permanent relief from pain, but a permanent shortening. This shortening may be much or little, many times depending on the attending surgeon in his removal of tissue, and also on his after-treutment and care of the case. If the case be young, we have every reason to believe that there will be a continuation of the growth of the femur, thus modifying more or less the permanent shortening. In my experience, those who have endured this operation are lame only from the shortening, while, in the result of a spontaneous cure, a very aggravating ankylosis and tilting of the pelvis accompanies it, with even a greater amount of shortening.

Much more might be said on this subject; cases could be cited of the various methods of treatment, 
time. I am satisfied that not all is accomplished by radical measures that should be expected. Still, with the improved methods at our hands, the greater knowledge of cause and effect, we may hope to accomplish much more than has ever before rewarded our efforts.

\section{A NEW PORTABLE ELECTRIC OUTFIT.} BY GUSTAVUS M. BLECH, A.B., M.D. CHICAGO.

Electricity as a therapeutic agent, while quite pop ular with a few specialists and wealthy practitioners is employed by the majority of general practitioners with no scientific precision, because of lack of suitable apparatus. The results are poor, for to obtain good results good apparatus is necessary. It is therefore for this reason that electricity is decried by many as a valueless agent, while in reality it is a very valuable means of curing a large number of nervous and muscular affections. The idea prevails among many practitioners that electricty can be administered scientifically only by means of large, stationary and expen-

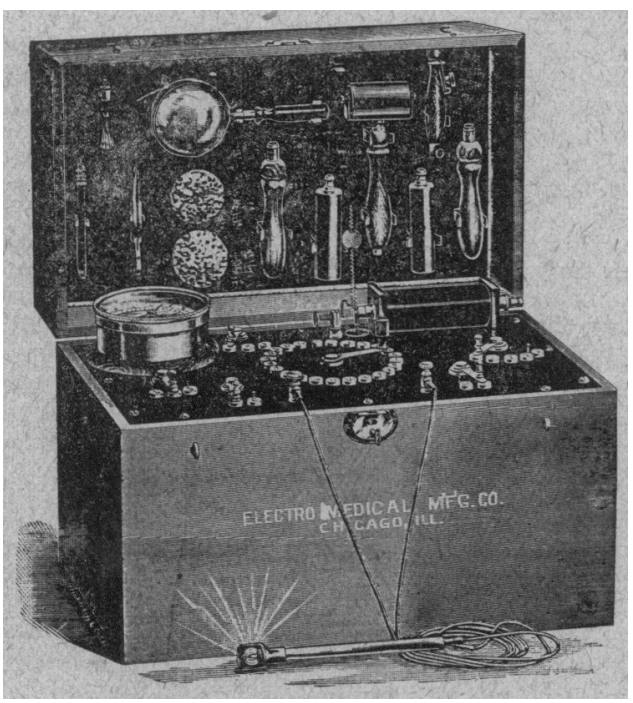

sive "machines." The price and impossibility of moving the batteries from the office to the bedside of the patient have proven objectionable features, preventing the general introduction and practice of electrotherapeutics. It is perhaps of interest to know that the most renowned specialists in Europe, for ex. ample Dr. Erb, who has become famous through his lectures and writings on eleotrotherapy, use, in their private practice, small portable batteries. Of course, the term "small, portable" is not to be confounded with the so-called family batteries, for self-treatment, which, as a rule, are not worth the material used on them. The erroneous idea that large liquid cells yield more electro-motive force and ampèrage than small dry cells has prejudiced the profession against anything but stationary cells. We know today that the size of the cell has nothing to do with its electromotive force and that a small dry cell about as large as a vaginal speculum will do more for a longer period of time than, for example, a Laciede sal ammoniac cell. The cost of renewing a dry cell is not larger than the refilling and keeping in good order of large liquid celle.

Knowing these facts, and to overcome the objections mentioned, with the co-operation of the manager of the Electro-Medical Mfg. Co., I have devised a combination battery which, while cheap, admits of the scientific admfnistration of galvanism, faradism, the practice of electrolysis, and the illumination of small lamps for diagnostic purpose. The following illustration gives a fair idea of its construction.

The battery has twenty-four cells, conuected to the galvanic circle, yielding 33 volts. The faradic current produced in the coil is even and smooth, but can also be regulated with Lindstrom's rheotome to from 100 to 4000 interruptions per minute. There is a selecting switch for primary and secondary currents. By means of a switch, connection is made with a strongly built milliampèremeter for the measuring of the galvanic current. Four extra large cells are connected to a German silver wire rheostat for the purpose of running a small incandescent lamp (25 hours) for the illumination of cavities-throat, vagina, rectum, etc.

The battery can be used for electrolytic work, such as the removal of superflous hair, warts, moles, etc., and has for that purpose an electric needle and holder, epilation forceps and magnifying glass. To the battery are added several sponge and metal electrodes, one roller electrode, one metallic brush and one interrupting handle, all which are fastened between strong clamps to the inner side of the cover.

\section{SOCIETY PROCEEDINGS.}

\section{Cincinnati Academy of Medicine. \\ Regular Meeting Feb. 13, 1899.}

Dr. J. W. Murpey read the paper of the evening entitled TREATMENT OF DISEASES OF THE MIDDLE EAR, WITH REPORTS OF CASES.

About one gixth of all ear cases come under the heading of chronic otorrhea. It has been proven that suppuration in the mucous membrane of the middle ear leads to hardness of hearing and deafness, through the impairment or destruction of the delicate structures contained therein. Incased in the deep bony cavity, freely communicating with the pneumatic cells of the mastoid, with important structures adjacent to or passing through it, we can see how any suppurative process of the ear is a standing menace to the life of the patient. He had seen in Professor Schwartze's clinic the skull of a boy 13 yeare old where the suppuration had continued through the bony wal of the lateral sinus, and sudden death followed. There had been no symptoms beyond a purulent discharge from the mid. dle ear.

In children in whom this disease is especially frequent, the various parts of the temporal bone are not united, but only held together by a fibrous matrix, and consequently secretions from the diseased mucous membrane may find an easy entrance to the meninges and brain itself. The bony covering of the Fallopian canal may be eroded and the horizontal semicircular canal opened through this suppuration. When the facial nerve is injured the paralysis is permanent. Pathogenic organisms may pass along the nerve sheaths, either toward the cerebellum, or upward and forward through the foramen enclosing the great petrosal nerve. According to Macewen, when the inflammation extends along the nerve sheaths it is more apt to give rise to leptomeningitis than brain abscess. Quoting the same authority, the essayist said : "When the tympanic cavity has become the seat of chronic suppuration with ulceration of the mucous membrane, extending into the antrum and mastoid cells, it becomes a standing menace to the safety of the patient. A person might as well have a charge of dynamite in the mastoid antrum or cells, as one can not know the moment when accidental circumstances may arise which may cause the infected matter to become widely disseminated all over the cerebrospinal system. Chronic otorrhea is much too lightly regarded, and is frequently considered as a mere inconvenience instead of a menace to life. It is a disease which advances insidiously, often without pain, until very extensive destruction of the middle ear and the mastoid antrum and cells, with thinning of their osseous walls and serious inflammation of the blood-vessels and the brain itself, occurs. One who has a chronic purulent otitis media is liable to have, with 